\title{
A CLINICAL TRIAL OF DEHYDROEPIANDROSTERONE (DIANDRONE)
}

\author{
BY \\ A. D. FORREST, J. DREWERY, K. FOTHERBY, and S. G. LAVERTY \\ From the Department of Psychological Medicine and the Clinical Endocrinology Research Unit (M.R.C.) \\ University of Edinburgh
}

It has been reported by Strauss and his coworkers (Strauss, Sands, Robinson, Tindall, and Stevenson, 1952; Sands and Chamberlain, 1952; Strauss and Stevenson, 1955, 1958) that dehydroepiandrosterone ("diandrone") altered the behaviour patterns and mental attitudes of a series of patients showing the "immaturity syndrome". Similar results have also been reported by Italian workers (Zubiani and Laricchia, 1953; Serra, 1953) who have found dehydroepiandrosterone to be of benefit in a number of psychiatric conditions (phobicobsessive psychoneuroses, neuropsychasthenia, psychopathic personality, involutive syndromes, and depressive psychoses) with the exception of schizophrenia.

However, no controlled trial of the effects of dehydroepiandrosterone has been performed. Since it appears that this substance is used in some psychiatric hospitals and as the endocrinological aspects of these reports are of interest, it seemed of value to perform a controlled trial of this substance.

\section{Methods}

After initial interviewing and random allocation to the trial group the patients were seen at weekly interviews for a period of seven weeks, by the psychiatrist for behavioural assessment and by the psychologist for performance rating.

The trial was conducted on the usual "double blind" principle. Subjects received placebo tablets or tablets of dehydroepiandrosterone for the first three weeks. No tablets were given in the fourth week and tablets were again given during the last three weeks. The dosage of dehydroepiandrosterone was $5 \mathrm{mg}$. per day for the first week, $10 \mathrm{mg}$. per day for the second week, and $20 \mathrm{mg}$. per day for the third week.

At each interview the patient was weighed and his behaviour at the interview assessed as regards mood, confidence, and aggressiveness. Specific questions were put to the subject:-

(1) How is your appetite?

(2) Have you noticed any change in your confidence as regards social occasions and reaction to arguments?

(3) How are you in your spirits?
(4) Have you noticed any change in your sexual activity?

(5) Are you sleeping well?

It was found in practice that these questions had always to be elaborated. Thus the question on sexual activity was broken down to include questions on sexual phantasy, masturbation, and overt heterosexual activity. On the basis of interview behaviour and the subjects' reported experience, assessments were made on mood, confidence and/or aggressiveness, and sexual behaviour. These assessments were aimed at recording changes rather than absolute values and were expressed in terms of a threepoint rating scale $(-1,0$, and +1$)$.

The psychological tests were intended to provide an independent and objective measure of any change in the patients' performance as the drug trial progressed. It was decided that a measure of output of work would be useful, and for this purpose two ad hoc tests were used. 8 The first consisted simply in having the patient write as many 0 s as possible continuously for a three-minute period. The production for each of the three minutes was noted. The second performance measure was obtained with a mechanical hand counter. The patient pressed the switch with his thumb and was instructed to put up as large a score as he could until told to stop ("clicker" test). The test period was one minute and readings were taken every 15 seconds to obtain a measure of work decrement.

Each test was administered twice with suitable rest pauses on each occasion that the patient was seen. It must be emphasized that as far as these tests are concerned this must be considered a pilot study. Control group data suggest that the tests are reliable enough for the present purpose. The " $0 \mathrm{~s}$ " test has a test-retest reliability coefficient of $0 \cdot 87$, and the "clicker" test has a reliability coefficient of $\mathbf{0 . 7 8}$. Both correlations are significant beyond the $\mathbf{0} \cdot 01$ level of confidence. However, data on the validity of these tests are meagre. In the control group $5 \mathrm{mg}$. of amphetamine increased productivity in both tests, but at the moment this sensitivity to an amphetamine-like effect is the extent of our information about them.

\section{Subjects}

We attempted to select patients for the trial in accordance with the criteria laid down by Strauss and Stevenson. 
TABLE I

PSYCHIATRIC ASSESSMENTS AT WEEKLY INTERVIEWS

\begin{tabular}{|c|c|c|c|c|c|c|c|c|c|c|c|c|c|c|c|c|c|c|c|c|c|}
\hline \multirow{2}{*}{ Weeks } & \multicolumn{7}{|c|}{$\begin{array}{c}\text { Confidence } \\
\text { and/or } \\
\text { Aggressiveness }\end{array}$} & \multicolumn{7}{|c|}{ Sexuality } & \multicolumn{7}{|c|}{ Mood } \\
\hline & 1 & 2 & 3 & 4 & 5 & 6 & 7 & 1 & 2 & 3 & 4 & 5 & 6 & 7 & 1 & 2 & 3 & 4 & 5 & 6 & 7 \\
\hline $\begin{array}{c}\text { Subjects } \\
\text { A } \\
\text { B } \\
\text { C } \\
\text { D } \\
\text { E } \\
\text { F } \\
\text { G } \\
\text { H }\end{array}$ & $\begin{array}{r}+1 \\
0 \\
+1 \\
0 \\
+1 \\
0 \\
+1 \\
+1\end{array}$ & $\begin{array}{r}-1 \\
0 \\
+1 \\
0 \\
-1 \\
0 \\
-1 \\
+1\end{array}$ & $\begin{array}{l}-1 \\
-1 \\
+1 \\
+1 \\
-1 \\
+1 \\
+1 \\
+1\end{array}$ & $\begin{array}{r}+1 \\
0 \\
-1 \\
0 \\
-0 \\
0 \\
0 \\
0\end{array}$ & $\begin{array}{r}+1 \\
-1 \\
+1 \\
+1 \\
+1 \\
0 \\
-1 \\
-1\end{array}$ & $\begin{array}{r}-1 \\
0 \\
+1 \\
+1 \\
+1 \\
+1 \\
+1 \\
+1\end{array}$ & $\begin{array}{r}-1 \\
0 \\
0 \\
+1 \\
0 \\
0 \\
-1 \\
+1\end{array}$ & $\begin{array}{r}\mathbf{0} \\
\mathbf{0} \\
\mathbf{0} \\
\mathbf{0} \\
\mathbf{0} \\
\mathbf{0} \\
+\mathbf{1} \\
\mathbf{0}\end{array}$ & $\begin{array}{r}0 \\
0 \\
0 \\
0 \\
0 \\
0 \\
-1 \\
-1\end{array}$ & $\begin{array}{r}\mathbf{0} \\
0 \\
0 \\
\mathbf{0} \\
0 \\
0 \\
+\mathbf{1} \\
\mathbf{0}\end{array}$ & $\begin{array}{r}0 \\
0 \\
0 \\
0 \\
-0 \\
0 \\
+1 \\
0\end{array}$ & $\begin{array}{r}0 \\
0 \\
0 \\
+1 \\
0 \\
0 \\
0 \\
0\end{array}$ & $\begin{array}{r}\mathbf{0} \\
+\mathbf{1} \\
\mathbf{0} \\
\mathbf{0} \\
\mathbf{0} \\
\mathbf{0} \\
\mathbf{0} \\
\mathbf{0}\end{array}$ & $\begin{array}{l}0 \\
0 \\
0 \\
0 \\
0 \\
0 \\
0 \\
0\end{array}$ & $\begin{array}{r}+1 \\
0 \\
+1 \\
0 \\
+1 \\
+1 \\
+1 \\
+1\end{array}$ & $\begin{array}{r}-1 \\
0 \\
+1 \\
0 \\
-1 \\
+1 \\
-1 \\
+1\end{array}$ & $\begin{array}{r}-1 \\
0 \\
+1 \\
+1 \\
-1 \\
0 \\
+1 \\
-1\end{array}$ & $\begin{array}{r}+1 \\
0 \\
-1 \\
0 \\
-1 \\
+\begin{array}{l}1 \\
0\end{array}\end{array}$ & $\begin{array}{r}+1 \\
0 \\
0 \\
+1 \\
0 \\
-1 \\
-1 \\
-1\end{array}$ & $\begin{array}{r}-1 \\
0 \\
+1 \\
+1 \\
+1 \\
0 \\
+1 \\
+1\end{array}$ & $\begin{array}{r}-1 \\
0 \\
0 \\
0 \\
+1 \\
+0 \\
-1 \\
+1\end{array}$ \\
\hline
\end{tabular}

Periods in bold type indicate administration of dehydroepiandrosterone.

Subject $\mathrm{E}$ was not interviewed during week 4 .

The essential features of the patients they studied were "constitutional inferiority", poorly developed libido, lack of confidence, social inadequacy, and shyness. These are fairly loose descriptive terms but do permit of a selection of subjects resembling closely the descriptions given in the case histories in the paper of Strauss and Stevenson (1955). These patients might also be classified as "vulnerable personalities" (Curran and Mallinson, 1944) or depressive psychopaths (Schneider, 1950).

The following brief summaries describe the salient features of our eight patients who were all single men.

Subject A.-Age 30, costing clerk, asthenic build, poor physical development. Dependent on mother and selfconscious in company. Had once had a girl friend but she had been "stolen" by one of his workmates. Always avoids arguments. Presenting symptom was that of depression.

Subject B.-Age 30, woollen mill operative, thin, asthenic type. Denied any current sexual interest or activity. Had once been engaged but pleased when fiancée broke it off-"she seemed to want it all her own way". Lives alone with mother, socially inhibited. Originally referred from Skin Department where he had been under treatment for dermatitis. To psychiatrist he also complained of inadequacy and depressive symptoms.

Subject C.-Age 26, cooper, thin and asthenic. Symptoms present for three years, consisting of true asthmatic attacks and episodes of tension in chest and throat. In addition complained of generalized anxiety and depressive feelings. Had been engaged but relieved when fiancée broke it off.

Subject D.-Age 23, electrician, small stature with poor physical development. Nervous boy, very young for his years and clearly dominated by ex-policeman father. Girl friend was apparently chosen for him by mother. Presenting symptoms were anxiety attacks coming on in situations evocative of claustrophobia. In addition complained of lack of confidence and feelings of depression.

Subject E.-Age 36, fireman in gasworks, athletic build, somewhat obese. Always shy and socially inhibited. Denied any heterosexual experience, had never actually taken a girl out. In 1946 accused of "voyeurism". He was found wandering about the grounds of W.R.N.S. establishment and put on probation for two years.

Presenting symptoms were depression and lack of confidence.

Subject F.-Age 19, apprentice bricklayer, small stature, obese. No social confidence or ambition, socially inhibited, only recreation was watching TV. Presenting symptoms were those of depression and lack of confidence. An episode of "voyeurism" had brought the patient to the notice of the police and this had accelerated his referral for psychiatric opinion. Patient absolutely denied any sexual activity or interest.

Subject G.-Age 20, undergraduate, asthenic build, nervous and lacking confidence. No sexual activity until the age of 17 with corresponding retardation in personality maturation. Presenting symptoms were lack of confidence and guilt over exhibitionistic impulses.

Subject H.-Age 20, undergraduate, poor physical development and late sexual maturation. Quiet, shy, unable to speak in company. Presenting symptoms were fear of blushing, anxiety about social occasions, and guilt feelings over sexual ruminations.

\section{Results}

Psychiatric Assessments.-These are shown in Table I.

It is clear that no consistent effect was observed during the period of administration of dehydroepiandrosterone. The number of positive and negative assessments recorded during the two periods are summarized in Table II. Although the

\section{TABLE II}

NUMBER OF POSITIVE AND NEGATIVE BEHAVIOUR ASSESSMENTS RECORDED IN TABLE I

\begin{tabular}{c|c|c|c}
\hline & Placebo & $\begin{array}{c}\text { Dehydro- } \\
\text { epiandrosterone }\end{array}$ & Total \\
\cline { 2 - 4 } $\begin{array}{c}\text { Number of positive } \\
\text { assessments }\end{array}$ & 22 & 26 & 48 \\
$\begin{array}{c}\text { Number of negative } \\
\text { assessments }\end{array}$ & 16 & 9 & 25 \\
\hline Total & 38 & 35 & 73 \\
\hline
\end{tabular}


total number of positive assessments is greater than the total number of negative ones this is probably of no significance and possibly reflects the design of the trial. At the end of the trial the psychiatrists and the subjects were asked to report whether, in retrospect, there was any difference between the first three weeks and the last three weeks. The psychiatrists and seven of the subjects reported no difference. One subject $(\mathrm{H})$ reported that the tablets had helped him but he could not differentiate clearly between the two periods of three weeks.

Weight Changes.-It was thought that weekly weight gains or losses of less than $3 \mathrm{lb}$. would be unlikely to be significant. Only two patients showed a weekly weight change of more than $3 \mathrm{lb}$. Subject $\mathrm{C}$ lost $5 \mathrm{lb}$. during the fourth week, before he had received any dehydroepiandrosterone, and subject $\mathrm{D}$ lost $3 \frac{1}{2} \mathrm{lb}$. during the third week of taking dehydroepiandrosterone. Thus at the end of the trial there was no significant change in weight compared with the pre-trial weights except in the case of subject $\mathrm{C}$ who had lost $8 \mathrm{lb}$.

Performance Tests.-One group of patients had placebo followed by dehydroepiandrosterone while the other had dehydroepiandrosterone followed by placebo. On a null hypothesis that dehydroepiandrosterone would not affect performance in the tests one would expect the growth curves over the seven-week period of testing to be closely similar. The more similar the pattern of scores for these two groups the less likely is it that dehydroepiandrosterone is affecting the patients' performance. A product-moment correlation for 0 s of $r=0.96$, was obtained, while on the clicker test $r=0 \cdot 67$. Both relationships are significant, and approximate to the reliability figures for the tests. It would seem from this that dehydroepiandrosterone was having no effect on performance which could be measured by these tests.

There was no significant difference between the means and standard deviations for the two tests calculated from all the results obtained while the patients were receiving dehydroepiandrosterone compared with those calculated while the patients were receiving the placebo (Table III).

TABLE III

MEANS OF SCORES IN THE PERFORMANCE TESTS OF ALL PATIENTS

\begin{tabular}{|c|c|c|}
\hline & $\begin{array}{c}0 \\
\text { Test }\end{array}$ & $\underset{\text { Test }}{\text { Clicker }}$ \\
\hline $\begin{array}{l}\text { Mean of scores while receiving dehydro- } \\
\text { epiandrosterone } \\
\text { Mean of scores while receiving placebo } \\
\text { tablets }\end{array}$ & $\begin{array}{l}327 \\
335\end{array}$ & 215 \\
\hline
\end{tabular}

\section{Discussion}

Dehydroepiandrosterone is quantitatively one of the major 17-ketosteroids in the urine and blood of normal humans. However, its biological function is still obscure. That it might possibly be involved in mental processes is suggested by reports that schizophrenics excrete more dehydroepiandrosterone than normal people (Mittelman, Romanoff, Pincus, and Hoagland, 1952; Reiss and Stitch, 1954) and by the variations in dehydroepiandrosterone excretion in patients with periodic psychoses. Thus the reports by Strauss and his colleagues and by the Italian workers that dehydroepiandrosterone is of use in the treatment of certain patients is of interest not only from the psychiatric point of view but also from the endocrinological aspect, especially since the doses used were within the physiological rather than the pharmacological range. Both the British and Italian psychiatrists have obtained effects with less than $10 \mathrm{mg}$. per day, the exact amount depending upon each individual patient, and both groups have reported the appearance of undesirable characteristics-increased irritability, excessive aggressivenesson overdose.

In view of the results reported by the above workers it was surprising that none of the eight patients treated by us responded to the dehydroepiandrosterone. The reason for this is not at all clear. The patients were selected to comply as closely as possible with the description given by Strauss et al. of the type of patient they had found to be responsive. Despite this, all except one of the patients (subject $\mathbf{H}$ ) in our series reported no subjective change, nor was there any response to the drug judged objectively in the series of interviews with a psychiatrist or in the tests of performance. This last finding would seem to be of some significance, for the performance tests appear to be sensitive to amphetamine and would probably have been affected by the changes reported by Strauss et al. had such changes taken place in our subjects.

The changes in personality reported by Strauss and Stevenson (1955) were confirmed in some patients by use of the Rorschach test. This test has not been used in the present study. Our psychological investigation has been orientated towards an assessment of productivity rather than personality.

In the trials conducted by Strauss et al. and the Italian workers the response to dehydroepiandrosterone was not compared with the response to placebo tablets although many patients had been treated with drugs, without benefit, before the trial of dehydroepiandrosterone.

Since Strauss and his co-workers described only those cases which improved with dehydroepiandrosterone it is not possible to calculate what 
proportion of their patients treated with dehydroepiandrosterone responded to this substance. A similar criticism applies to the paper of Serra (1953). Zubiani and Laricchia (1953) have classified the response of their patients into five groups: (1) notable improvement, (2) distinct improvement, (3) slight improvement, (4) no change, and (5) deterioration. Excluding the group of schizophrenics, out of 107 patients treated, 48 were in group 1, 35 in group 2, 15 in group 3, and 9 in group 4. No patients deteriorated while on treatment. Thus if one takes into account only those patients who showed a notable improvement then almost half of the patients treated fall into this group.

It must be concluded that this trial has failed to reveal any therapeutic effect attributable to dehydroepiandrosterone, and although the number of patients studied has been small, on a statistical basis it would not be expected that the conclusion would be greatly different if a larger number of patients were studied. We do suggest, however, that the activity of dehydroepiandrosterone can only be decided when a properly controlled trial is performed on a large number of patients and with methods of evaluation of the behavioural state of the patient more specific than those which Strauss et al. or the Italian psychiatrists have employed.
Summary

The effect of dehydroepiandrosterone on eight psychiatric patients showing constitutional inferiority, lack of confidence and social inadequacy has been investigated.

This compound had no effect on behaviour judged objectively or subjectively nor did it affect the performance in two productivity tests.

We wish to thank Dr. C. L. Hewett of Organon Ltd. for the dehydroepiandrosterone and placebo tablets and Professor A. Kennedy under whose care the patients were during the period of investigation.

\section{REFERENCES}

Curran, D., and Mallinson, P. (1944). J. ment. Sci., 90, 266.

Mittelman, A., Romanoff, L. P. Pincus, G., and Hoagland, $H$ (1952). J. clin. Endocr., 12, 831.

Reiss, M., and Stitch, S. R. (1954), J. ment. Sci., 100, 704.

Sands, D. E., and Chamberlain, G. H. A. (1952). Brit. med. J., 2,66 .

Schneider, K. (1950). Die Psychopathischen Persönlichkeiten, 9th ed. Vienna.

Serra, C. (1953). Minerva med., Deuticke, 44, (1) [Parte Sci.], 1731.

Strauss, E. B., Sands, D. E., Robinson, A. M., Tindall, W. J., and Stevenson, W. A. H. (1952). Brit. med. J., 2, 64.

- , and Stevenson, W. A. H. (1955). J. Neurol. Neurosurg. Psychiat. $18,137$.

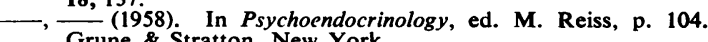

. [Parte Sci.]. 